\title{
Portugueses no meio rural paulista (1900-1950)
}

\author{
Maria Christina Siqueira de Souza Campos* \\ Paulo Henrique Lunardelo **
}

\section{Introdução}

O presente texto é Resultado de um trabalho intitulado Famílias Portuguesas no Meio Rural Paulista (1900-1950), parte integrante de um projeto mais amplo levado a efeito junto ao CERU, voltado ao estudo dos imigrantes portugueses no Estado de São Paulo (metrópole e interior) durante o século XX. Focalizou famílias portuguesas que se deslocaram na primeira metade do século passado de Portugal para o interior do Estado de São Paulo, para se dedicarem especialmente a atividades desenvolvidas no meio rural, seja como trabalhadores rurais (colonos), seja como inspetores, supervisores, administradores de fazendas, ou até como proprietários rurais. Buscou analisar as práticas e representações desses imigrantes portugueses e seus descendentes no que se refere à vida familiar e à sua participação na vida social mais ampla, incluindo aí o desempenho de atividades econômicas. Assim, o estudo analisou a trajetória desses imigrantes e seus descendentes desde o tempo em que

\footnotetext{
* Professora livre docente do Departamento de Economia da FEA-USP (Campus de Ribeirão Preto) e diretora-presidente do Centro de Estudos Rurais e Urbanos (CERU-USP).

** Estudante do curso de Economia da FEA-USP (Campus de Ribeirão Preto); bolsista do CNPq no projeto.
} 
a família residia em Portugal, seu translado para o Brasil e a chegada em diferentes regiões do interior do estado de São Paulo, bem como as atividades econômicas por eles desenvolvidas na terra de origem e na de adoção e o grau de relacionamento mantido com brasileiros natos e representantes de outras comunidades imigrantes.

As circunstâncias especiais que marcaram não só a colonização portuguesa no Brasil - ausência de grupos autóctones fortes, que poderiam ter feito frente ao colonizador, e manutenção de um governo ainda ligado por fortes laços à nação portuguesa - fizeram com que a ligação do Brasil com Portugal se mantivesse firme, mesmo depois do processo de independência no começo do século XIX. Assim, quando a crise econômica presente na zona rural lusitana se acentuou, o Brasil se apresentou como o primeiro destino para os portugueses desejosos de tentar a vida em novas terras. A legislação portuguesa na época, que determinava que a herança da propriedade fosse para o filho primogênito, só fez aumentar a necessidade de os outros filhos procurarem novas terras para poderem sobreviver em condições razoavelmente dignas.

Por outro lado, o Brasil estava em fase de expansão econômica, com o sucesso da lavoura cafeeira na segunda metade do século XIX, que se espalhava rapidamente pela região oeste do Estado de São Paulo. A necessidade de mão-de-obra para a cultura do café, em um momento em que a escravidão negra estava se aproximando visivelmente de seu fim e em que o sistema capitalista estava penetrando a atividade agrícola, fez com que tivessem sido envidados esforços por parte tanto dos diretamente interessados (cafeicultores) como das autoridades provinciais para atrair trabalhadores estrangeiros para a agricultura em expansão. Foi assim que começaram a chegar os imigrantes, principalmente italianos, portugueses, espanhóis e, mais tarde, japoneses.

Tratou-se este de um estudo qualitativo e, como tal, se baseou na coleta de relatos orais de portugueses e seus descendentes, assim como na análise de documentos existentes em órgãos oficiais e entidades portuguesas ou em poder das próprias famílias. Seu referencial teórico foi o pensamento de Pierre Bourdieu, que fundamentou a análise dos relatos orais colhidos. A época abrangida pelo estudo corresponde a um momento anterior à entrada da imigração no debate público, de acordo com as palavras desse autor (Bourdieu, 1998, p. 11). 
Para se ter acesso a esses imigrantes foram anotados todos os dados constantes das fichas de imigrantes registradas no arquivo do Consulado de Ribeirão Preto. Além das fontes orais, teve um especial destaque como fonte de dados a documentação colhida tanto no Arquivo Municipal de Ribeirão Preto (imprensa da época e fichas de registro de terras adquiridas pelos imigrantes), como na Associação Comercial e Industrial (ACI) desse município. Embora só tenha sido possível a consulta às fontes existentes em Ribeirão, tanto pela falta de tempo como de bolsistas e recursos, ainda assim esses dados são muito ricos, referindo-se muitas vezes à região e não só ao município.

O sub-projeto Famílias Portuguesas no Meio Rural Paulista procurou analisar o processo de construção de novas identidades de famílias de portugueses e seus descendentes que vieram para o interior paulista na primeira metade do século passado. Em uma abordagem sócio-antropológica, este estudo focalizou diferentes campos da vida social: vida familiar, trabalho, educação, cultura, lazer, religião e política.

A emigração é um fenômeno estrutural da sociedade portuguesa devido ao contínuo movimento de saídas vigente desde o período das navegações, traço esse que só no final da década de 1980 começou a se modificar. O Brasil, durante o século XIX e nas primeiras décadas do século XX, foi o destino principal desse movimento em busca de novas oportunidades de vida, principalmente na agricultura. Outros fluxos consideráveis ocorreram em direção aos EUA, principalmente de ilhéus atlânticos, para trabalhar no setor industrial, e para a Argentina, alguns países da África e mais recentemente para a França, Alemanha e alguns outros países da Europa Central. "Aquilo a que posteriormente chamaremos comunidades portuguesas foi o resultado de uma continuidade de residência de núcleos populacionais fora do espaço europeu, prolongado por casamentos endogâmicos ou mistos e pela sucessão das gerações daí advindas" (Rocha-Trindade, 1988, p. 314).

No Brasil, a entrada, no período da grande imigração, foi de 500 mil portugueses, e a comunidade de descendentes pode ser estimada na ordem de 1,5 milhão de pessoas concentradas principalmente no Estado de São Paulo e Rio de Janeiro. Este número é impreciso devido à rápida integração que os portugueses tiveram no país pelo fato de o Brasil ter sido antiga colônia de Portugal, o que facilitou a incorporação de várias características e elementos como: a religião católica, a 
língua portuguesa, bem como vários traços da cultura e tradição do povo luso.

Ao virem para o Brasil, os imigrantes portugueses já tinham a intenção de aqui permanecer e os que retornaram ao país de origem o fizeram por causa das condições adversas que aqui encontraram. A perspectiva de permanecer no Brasil contribuiu certamente para uma integração mais rápida de todos os imigrantes vindos desde a segunda metade do século XIX, em especial dos portugueses.

\section{Os Imigrantes portugueses no meio rural paulista}

\subsection{Os portugueses no interior de São Paulo}

Embora os imigrantes originados da Itália tenham constituído o maior contingente a vir para São Paulo no século XIX, as difíceis condições de trabalho fizeram com que a Itália proibisse, já em 1902, a imigração subvencionada, devido às notícias de maus tratos nas fazendas de café veiculadas nesse país. Seguindo seu exemplo, igual medida foi adotada por Portugal em 1911, mas isso não provocou uma queda na quantidade de mão-de-obra disponível, pois depois de 1902 os trabalhadores espanhóis e portugueses já haviam suplantado os italianos e, a partir de 1908, passaram a entrar também os japoneses, sendo estes mais permanentes na agricultura do que os italianos, com mostra a tabela abaixo:

Imigrantes desembarcados em Santos empregados na Agricultura / Coeficiente de Assentamento Permanente entre 1908 e 1933

$\begin{array}{lllll}(\mathrm{A}) & (\mathrm{B}) & (\mathrm{C}) & (\mathrm{D}) & (\mathrm{E}) \\ \text { Japoneses } & 139.199 & 137.584 & 98,84 & 96,3 \\ \text { Espanhóis } & 207.326 & 164.306 & 79,25 & 91,3 \\ \text { Italianos } & 199.201 & 100.553 & 50,48 & 41,3 \\ \text { Portugueses } & 265.765 & 129.027 & 48,50 & 93,1\end{array}$

(A - nacionalidade; $\mathrm{B}$ - número total de imigrantes; $\mathrm{C}$ - número de trabalhadores agrícolas; D - porcentagem na agricultura; E - coeficiente de permanência de trabalhadores agrícolas; em \%. Fonte: F. Maurette, apud Stolcke, 1986, p. 66.) 
Num período de vinte anos não houve um aumento relevante na remuneração monetária dos colonos nas fazendas de café. Os fazendeiros reinvestiam seu lucro na expansão das fazendas, já que não havia pressão alguma para que aumentassem a quantia fixa paga aos colonos. O colono, ao optar vir para a região nordeste paulista, não estava interessado na remuneração fixa e sim nas plantações que poderia realizar nas terras intercafeeiras, o que lhe possibilitava alguma acumulação financeira. Mas nem sempre suas expectativas condiziam com a realidade, havendo grande instabilidade dos colonos na lavoura.

Pode-se dizer que a grande imigração nos moldes em que vinha se processando desde os finais do século XIX terminou em 1930. Com a Constituição de 1934 foi introduzido o regime de cotas restringindo a imigração estrangeira no Brasil. O problema da mão-de-obra para a lavoura cafeeira consolidou-se depois da Segunda Guerra Mundial. Houve quase uma completa paralisação da imigração estrangeira para as áreas rurais e também um êxodo tanto dos colonos como dos trabalhadores nacionais para os centros urbanos. As razões para esse êxodo eram várias, mas principalmente pode ser citado o tratamento dado ao trabalhador nas fazendas de café. Os direitos que os operários das zonas fabris ou os trabalhadores das cidades conseguiam como aposentadoria, escolas para os filhos, assistência médico-hospitalar e dentária, regime alimentar nos refeitórios das fábricas etc., inexistiam para os trabalhadores agrícolas.

\subsection{Os entrevistados e sua presença nos diferentes campos}

Foram realizadas trinta entrevistas no período de março/1998 a março/2000, sendo onze delas com pessoas da primeira geração. Todas vieram para trabalhar no meio rural paulista, em especial na região de Ribeirão Preto. De modo geral tratam-se de pessoas idosas, com idade variando entre 68 e 92 anos. Sua origem é, principalmente, do norte de Portugal (região do Minho) e um da ilha da Madeira. Vieram para o Brasil atraídos por cartas de amigos ou parentes que os informavam sobre as novas oportunidades de trabalho ou, ainda, através de contratos firmados com os fazendeiros já antes da vinda, recebendo, neste caso, a passagem do futuro empregador. Também foram realizadas entrevistas com doze pessoas da segunda geração e duas pessoas da terceira geração. 
Uma característica comum aos entrevistados da primeira geração, pertencentes ao primeiro grupo de emigração que vai do final do século XIX ao começo do século XX, é ter sido sua emigração motivada por dificuldades econômicas com a perspectiva de uma melhora de vida no Brasil. A maioria dos entrevistados do primeiro período de imigração é, assim, originária da zona rural em Portugal ou de pequenas aldeias e se dedicava principalmente à agricultura em terra própria ou de terceiros. É preciso não esquecer que nesse período Portugal passava por um período de instabilidade política e econômica, o que levou os emigrantes a virem para o Brasil para se dedicar principalmente à agricultura, setor em clara expansão neste país. Já a emigração ocorrida no segundo período, no pré e pós-guerra, foi motivada ora por razões econômicas, ora por divergências políticas, devidas à ditadura de Salazar; estes imigrantes possuíam um nível educacional mais elevado e vieram para se dedicar a atividades urbanas.

A viagem de Portugal para o Brasil era feita de navio, durando aproximadamente vinte dias, realizada em embarcações com poucas condições de higiene e, de um modo geral, financiada com recursos próprios ou da família. Quando financiada por terceiros, o imigrante recém-chegado tinha que trabalhar um ou dois anos para pagar a dívida.

Ao chegar ao Brasil, no porto de Santos, do grupo da primeira geração, sete entrevistados se dirigiram diretamente para o interior do Estado de São Paulo, para as fazendas de produção de café; os restantes permaneceram na cidade de São Paulo, só mais tarde se dirigindo para o interior paulista.

No que se refere aos imigrantes e a seus descendentes, a educação formal é uma das principais formas de integração com a comunidade receptora, pois é nesta que se ampliam as suas redes sociais, entra-se em contato com a cultura e o modo de vida "novo".

Quanto à educação formal, os pais dos entrevistados eram majoritariamente analfabetos e uma característica da primeira geração é também o baixo grau de escolaridade; já os entrevistados da segunda geração possuem uma educação mais avançada, mas, como nos primeiros tempos não havia muitas escolas e era necessário ajudar os pais na lavoura, o nível educacional constatado é ainda reduzido, havendo só alguns que se fixaram na cidade conseguido atingir o nível superior. Todos os descendentes de terceira geração possuem um nível 
educacional mais avançado e atingiram o ensino superior com muita freqüência.

No Brasil, tendo em vista que este sempre foi um país de imigração, pelo menos até duas décadas atrás, não houve uma educação formal visando à continuidade de valores e tradições estritos de um grupo imigrante, salvo as comunidades de origem alemã e italiana no sul do país que proporcionavam a seus membros toda uma educação de acordo com os ditames dos costumes de cada país, com o emprego da língua materna. Isto também aconteceu com um grupo bem menor, os japoneses, que se mantiveram unidos, principalmente em São Paulo, em torno de uma comunidade coesa e homogênea.

Considerando o grupo étnico como um tipo organizacional peculiar culturalmente diferenciado dos outros, os portugueses não constituíram uma comunidade fechada e não criaram uma estrutura educacional estrita para os seus descendentes, já que as novas gerações poderiam freqüentar sem problemas de língua as escolas brasileiras.

A transmissão de valores e tradições de um determinado grupo étnico é pressuposto básico para a continuidade e sobrevivência deste, que passa para as gerações futuras a cultura e o modo de vida aceitos por esta sociedade. "A transmissão cultural entre as gerações é tão antiga quanto a humanidade, nascida que é da condição humana fundamental [...], sendo a cultura a essência daquilo que converte indivíduos humanos em grupos" (Thompson, 1993, p. 9), e a sua transmissão pode-se dar de várias formas, entre as quais assumem papel muito importante tanto a educação formal como a educação informal.

A educação informal tem para a grande maioria das comunidades um papel fundamental na transmissão dos valores, pois é a principal forma de socialização e de enriquecimento cultural que possuem. Esta educação é advinda do contato com os familiares e com amigos que lhes passam principalmente valores, costumes e tradições próprias do grupo que ficam marcadas para toda a vida.

"O papel da família na transmissão cultural intergeracional é tão antigo quanto a história do homem. E, apesar da importância de outros canais, em particular o grupo de amigos, assim como de instituições mais especializadas, como a oficina, a escola e a igreja, o papel da família continua praticamente 
insubstituível. Ele inclui não somente a transmissão da memória familiar e do grupo, mas também os valores e aspirações sociais, visões de mundo, habilidades domésticas, modos de comportamento, modelos de parentesco e casamento - tudo isso resultando na condensação das experiências características particulares que Bourdieu preferiu identificar pela antiga palavra babitus." (Thompson, 1993, p. 9-10)

Percebe-se, através da leitura das entrevistas, a importância que a educação informal teve para a grande maioria dos entrevistados, principalmente para os da primeira geração, pois foi a principal forma de socialização e de participação cultural que tiveram. Esta educação foi advinda do contato com os familiares e com amigos que lhes passaram principalmente valores, costumes e tradições próprias do grupo que ficaram internalizados para toda a vida.

No âmbito familiar, a mulher tem um papel fundamental na transmissão da cultura de determinado grupo étnico. Por tomar conta dos filhos e ser a responsável pelos afazeres domésticos, fica mais tempo em contato com eles e os educa da melhor maneira possível, transmitindo-lhes a visão de mundo de sua família e de sua classe, que também reflete a de seu grupo.

Com as modificações ocorridas principalmente nas sociedades ocidentais a partir dos anos 1960, em que a mulher passou a gozar de uma maior liberdade sexual e começou a ocupar um maior espaço no mercado de trabalho, pode-se concluir que, em determinados grupos, notadamente nas famílias de origem imigrante, a transmissão dos valores e da cultura para os filhos ficou de certo modo prejudicada, em virtude de sua principal transmissora estar agora pouco presente. Isso pode ajudar a explicar, pelo menos em parte, que a tradição de determinados grupos tenha diminuído nos últimos anos. Mas certamente o fato de as novas gerações estarem convivendo diariamente com a população da sociedade de acolhimento deve ser o fator mais importante para a atenuação da importância dos padrões da cultura de origem.

As famílias dos imigrantes que foram para a zona rural eram extensas, com vários filhos, em virtude do fato de que quanto mais braços para o cultivo da lavoura, mais elevados seriam os recursos daí advindos para o sustento da família e também porque o uso de méto- 
dos contraceptivos ainda não tinha se disseminado. As famílias que se dirigiram para as cidades tinham em média três filhos por casal, por causa do maior custo para criá-los, da não importância de muitos braços para o sustento da família e possivelmente da difusão mais fácil de informações e de métodos anticoncepcionais.

Um dos pré-requisitos para a formação de uma comunidade coesa é o casamento endogâmico ou misto e a contínua afluência de pessoas da mesma origem para uma determinada região. Em Ribeirão Preto e na região não houve praticamente casamentos intragrupo. Os imigrantes analisados tinham um bom relacionamento com os outros grupos de imigrantes (italianos, espanhóis, alemães etc.) e com os brasileiros, o que fazia com que todos vivessem a mesma situação e os mesmos problemas relacionados às dificuldades de integração na terra estranha, sendo de natureza semelhante os rompimentos e o processo de reconstrução da identidade, guardadas, evidentemente, as especificidades. No comentário de um entrevistado, o Sr. Emílio, este ponto torna-se explícito: "Eu fui recebido de braços abertos por toda a colônia italiana, inclusive tive uma namorada italiana, filha de italiano aí. Eu fui sempre... depois apareceu, né (aponta para a esposa), eu fui muito bem recebido, sempre digo nas reuniões que eu devo muitas obrigações à colônia italiana."

Tendo em vista esse bom relacionamento, o namoro e o casamento aconteciam freqüentemente com cônjuges de outras etnias, resultando que, dos entrevistados, apenas três se casaram com imigrantes portugueses. Isso, acrescido do fato de que o fluxo migratório praticamente cessou nos anos 1970, leva-nos a dizer que a comunidade portuguesa está se "diluindo" na brasileira, pelo menos no interior do Estado de São Paulo.

A família é muito valorizada pelos entrevistados, sendo encarada como a base para o crescimento social e pessoal. Há reuniões freqüentes, em dias comemorativos ou finais de semana, com os familiares mais próximos e contatos ou encontros menos regulares com os parentes mais distantes.

A divisão das tarefas domésticas e das relações em casa era bem clara e definida. Aos homens cabia o sustento da família através de um trabalho remunerado, normalmente a supervisão das contas domésticas e a decisão final na maioria dos assuntos. À mulher ficava a incumbência 
da criação dos filhos e a manutenção e transmissão dos valores e tradições, além dos afazeres domésticos, como da limpeza e os cuidados com a alimentação. Aos filhos, restava o papel de obedecer às ordens dos pais, trabalhar ajudando a família em sua fonte de renda e respeitar as tradições do grupo. Deviam estudar na época adequada e principalmente ajudar os pais no trabalho. Essas características são bem marcantes nos entrevistados do primeiro grupo de imigração, sendo fortemente influenciadas pelos papéis definidos na sociedade em geral de acordo com o pensamento vigente da época. Na fala de um entrevistado, isso fica bem claro:

"C: E da sua lembrança... Essa já é uma pergunta só para entender como era a vida doméstica...

M: Lá em Portugal ou aqui?

$\mathrm{C}$ : Na sua casa, quem dava as cartas, ou seja, quem tomava as decisões?

M: Bom, lá em Portugal era a minha mãe, não tinha jeito.

$\mathrm{C}$ : E aqui no Brasil?

M: Aqui no Brasil a decisão era do meu pai. Naquela época era um machismo tremendo. Ainda hoje tem, então imagine naquele tempo! A mulher, sabe, também tinha uma coisa, a minha mãe não era independente quanto à vida financeira. Hoje a mulher trabalha e pode muito bem dar um chute no marido, que se dane o marido. É por isso que eu sempre falava para a minha filha... Ela tinha uns catorze ou quinze anos e ela era meio malandrinha para estudar e eu sempre falava prá ela: 'Você tem que estudar, minha filha. Tem que estudar, se formar, porque se você se casar com um vagabundo, com um jogador, um salafra, você abandona-o e eu estou pronto para receber você de novo em casa. Se você for uma dona de casa, você não terá coragem nem de responder para o seu marido e você vai ter que agüentá-lo para o resto da sua vida'. Eu falei isso prá ela muitas vezes. Ela tinha uns doze, treze anos e tinha que estudar na marra."

Essas características são bem marcantes nos entrevistados do primeiro grupo de imigração, sendo fortemente influenciadas pelos papéis e padrões definidos na sociedade em geral, de acordo com o pensamento vigente da época. De acordo com um entrevistado: “Às 
vezes eu ajudava minha esposa de forma modesta, ora tirava a mesa do almoço, ora lavava a louça no fim de semana" (Sr. Augusto).

Já para os entrevistados de imigração mais recente e os de segunda e terceira geração, a divisão das tarefas do lar não é tão rigorosa. Com o processo de industrialização e urbanização e a revolução nos costumes a partir da década de 1960, as relações entre pais e filhos foram profundamente modificadas. As mulheres não ficaram mais destinadas apenas às atividades do lar e entraram cada vez com mais força no mercado de trabalho, passando a ter um peso muito maior nas decisões em casa. Os filhos começaram a ter maior liberdade para expressar seu gosto, tomar decisões que afetem sua vida e agir independentemente, buscando sempre a sua "autonomia", modificações essas que acompanharam tendências correntes nos países ocidentais.

A severidade dos pais na criação dos filhos era tanta que um entrevistado relatou que para fazer com que seus filhos não brigassem mais "ele fazia os dois se beijarem na boca, colocava uns grãos de milho e mandava eles ajoelharem lá por meia hora e ainda tinham que pedir perdão um para o outro olhando cara-a-cara".

Nos entrevistados de segunda e terceira geração a educação formal supera em importância na sua memória a educação informal, o que fica patente ao se constatar o distanciamento desses entrevistados em relação às tradições do grupo.

Em alguns casos as mulheres tiveram uma "educação especial" em relação aos homens, com uma maior carga dos valores tradicionais portugueses, produto da visão machista vigente na época. Elas tinham menos liberdade e eram dependentes dos pais ou dos irmãos mais velhos, que as protegiam para deixá-las "puras e intactas" para seu futuro marido. Em outros casos a educação dada a homens e mulheres era praticamente igual, "só que os mais novos, tanto os homens quanto as mulheres, eles deixavam um pouquinho mais à vontade, digamos assim ‘aos olhos do mundo' e isso não é bom” (Sr. Emílio).

Outro aspecto importante dessa educação e da transmissão de valores é a religiosidade marcante da primeira geração, sendo os imigrantes majoritariamente católicos. Mas, nas outras gerações, percebese que eles se tornaram católicos não-praticantes ou crentes de outras igrejas. Nesse ponto fica evidente a incorporação dos valores e modo de vida tipicamente brasileiro, como o catolicismo não praticante. 
No relato do Sr. Francisco esse traço fica bem claro: "Mas eu sempre fui muito religioso. Religioso eu sou até hoje, graças a Deus... Tem um só [membro de sua família] que é crente, mas todos os outros são católicos. Nem todos são praticantes, mas pelo menos têm muita fé, graças a Deus".

Além da religião, os valores transmitidos de pais para filhos foram basicamente a importância do trabalho, a honestidade, a honra e a união da família. Em quase todos os relatos esses eram os princípios que os pais mais gostariam que os filhos adquirissem e transmitissem para os seus descendentes.

Tais valores ficam bem visíveis no relato do Sr. Francisco:

"Olha, o que ele [o pai] ensinava era a religião. Ele sempre dizia também 'nunca roube de ninguém, mas trabalhe, seja honesto consigo mesmo. Se vocês forem assim, vocês irão vencer tudo na vida'. Ate hoje eu sou muito honesto. Não sei dar prejuízo para ninguém. Eu desconheço uma pessoa que diga que eu estou devendo um centavo. Eu dei prejuízo somente para duas pessoas até hoje, que eu sei que eu dei, mas um mora no Mato Grosso, já fui lá duas vezes depois que saí do exército, eu não consegui encontrá-lo, mas assim que encontrá-lo, irei pagá-lo. E é uma mixaria. É um dia do serviço que ele fez por mim, sabe?"

Em relação à culinária portuguesa, esta é principalmente compartilhada em datas comemorativas, como Sexta-feira Santa, Natal e outras; são apreciados costumeiramente o bacalhau, as sardinhas, o caldo verde, os vinhos portugueses e outros pratos típicos. $\mathrm{Na}$ culinária fica bem clara a "miscigenação" com os outros grupos: devido ao casamento ou outro motivo preparam-se comumente pratos tipicamente brasileiros e italianos. Para exemplificar, leia-se o que dizem dois entrevistados:

"Olha, era mais assim, durante um certo tempo era mais comida portuguesa, aí depois que minha mãe casou com o finado meu pai, que era mineiro, então ela fazia muita comida mineira. Aí diversificou, foi misturando a comida mineira com a portuguesa..." 
"Aqui continuou os hábitos, mas eu geralmente... tem alguma diferença. Eu gosto muito da comida portuguesa porque é uma variedade. Aqui é o arroz e feijão e... tem muita coisa boa, mas eu ainda estou mais para a comida portuguesa."

Outra característica comum é o fato de todos os entrevistados terem dito que nunca sofreram preconceito ou discriminação, "assim não se notou qualquer sinal de isolamento que tenha levado à formação de guetos ligados a colônias de imigrantes".

Eles também não tiveram e não vêem problemas com as piadas sobre portugueses, alguns até se divertem, como o Sr. Manuel: “Às vezes eles contam piadas para mim, tem hora que eles pegam para contar piadas sobre portugueses. Eles dizem 'Ah, Manuel! Conta aí para os italianos'. Eles brincam assim: 'Se a gente contar sem você por perto, não tem graça'. Eu não me importo com isso, eu dou risada com eles”.

Somente o filho de um entrevistado disse que, quando era menino, se sentia humilhado quando os colegas da escola primária contavam piadas sobre portugueses. A esse respeito seu pai disse que considera as pessoas que contam essas piadas pouco cultas.

Os entrevistados da primeira geração possuem uma identidade dúbia, sentem-se portugueses e brasileiros ao mesmo tempo, tendo alguns se naturalizado brasileiros. Mas em geral eles ainda possuem a identidade portuguesa, o que fica claro no relato de um entrevistado: "Olha, o sangue não nega a raça. Eu sou sempre português, mas a minha segunda pátria é o Brasil.”

Já os de segunda e terceira geração sentem-se brasileiros, mas nutrem um carinho todo especial por Portugal. Alguns se interessam pelo país e pelas histórias dos antepassados, mas a sua pátria é o Brasil. Alguns descendentes se interessaram em retirar passaporte português, mais com o intuito de poder viajar pela Europa com maior liberdade do que pelo orgulho de possuir um passaporte português ou motivados pelo desejo de morar em Portugal.

Um ponto interessante sobre os entrevistados da terceira geração é que eles vão se distanciando cada vez mais dos valores e da cultura de Portugal e da família, já não vendo necessidade de manutenção das tradições tipicamente portuguesas como a religiosidade, as festas juninas e a reunião da família em datas especiais, evidenciando um individualismo comum nos tempos atuais. 
Dos entrevistados, seis pessoas afirmaram que mantêm contato com entidades portuguesas, como a Casa de Portugal, a Beneficência Portuguesa, entre outras, mas a maioria não mantém nenhum vínculo devido ao fato de residirem em cidades pequenas que possuem uma diminuta comunidade de origem portuguesa ou por falta mesmo de interesse. Caso excepcional é o Sr. Manuel, que há cinqüenta anos participa de entidades representativas portuguesas e que teceu o seguinte comentário: “Quanto à Beneficência [Portuguesa, hospital fundado pelos portugueses], já fui provedor, secretário, tesoureiro, enfim já fiz tantas coisas ali. Agora a gente tem que dar lugar para outras pessoas porque a gente já não tem a mesma vitalidade."

O cônsul em Ribeirão Preto, Sr. Hermínio, reclama que atualmente é baixa a participação dos portugueses nas suas entidades representativas, dizendo que no Clube Português há muito mais brasileiros do que descendentes de portugueses. Uma provável causa seria que os descendentes de portugueses já não se sentem mais pertencentes à comunidade lusa e não têm interesse em participar de suas entidades representativas, encarando possivelmente a ligação com entidades portuguesas como um meio de os segregarem da sociedade local e podendo talvez prejudicá-los em seus negócios.

Alguns entrevistados adquiriram um certo destaque nas comunidades em que estão inseridos. Um exemplo é o Sr. Emílio, em Tambaú, que foi um dos fundadores da Santa Casa dessa cidade, presidente da Cooperativa de Produtores de Cerâmica e vice-presidente do Clube Recreativo; em 1981 foi agraciado com o titulo de cidadão honorário da cidade. Outro caso é o Sr. Manuel, que vive em Santo Antônio da Alegria, pequeno município da região de Ribeirão Preto. Tornou-se personalidade de destaque na comunidade local, reformou primeiramente a capela existente e depois financiou e acompanhou de perto a construção da igreja matriz na cidade. $\mathrm{Na}$ inauguração desta, foi a pessoa que entregou as chaves da igreja ao bispo que iria presidir a cerimônia de sagração.

Os destaques nessas sociedades foram proporcionados pelo espírito de trabalho, honestidade e liderança característica própria da comunidade portuguesa, bem como o bom relacionamento com os outros grupos.

Alguns entrevistados que deixaram parentes em Portugal mantêm contato através de cartas e telefonemas, enquanto os de melhor condição 
financeira vão às vezes visitá-los, bem como os amigos, em Portugal. Um entrevistado disse já ter ido dezoito vezes para Portugal visitar os parentes e duas para os EUA. Já os de baixa condição financeira mantêm pouco contato e alguns não deixaram ou desconhecem parentes em Portugal. Alguns entrevistados mostraram ter acompanhado de perto e outros disseram que militaram em movimentos políticos em Portugal (por exemplo, na Revolução dos Cravos), mas que no Brasil não possuem vínculos políticos ou partidários.

Uma outra característica em comum é a ascensão social e econômica - fruto de uma vida árdua e sistemática dedicada ao trabalho -, a acumulação de bens materiais e a elevação no padrão de vida. Os entrevistados dedicaram-se a variadas profissões, mas em maioria no período inicial se dedicaram à agricultura e com o passar do tempo a outras atividades, como o comércio, atividades empresariais de modo geral, profissões liberais, artistas e outras funções, tendo atingido um bom nível sócio-econômico.

Exemplo de trajetória é o Sr. Emílio, que trabalhou na agricultura em Portugal com os pais até os dezoito anos, quando, em 1929, emigrou para o Brasil sozinho. Durante alguns anos foi barbeiro, mas a sua principal atividade foi no ramo da olaria. Trabalhou alguns anos no Sul do país em uma cerâmica de um de seus tios e depois de casado conseguiu montar uma cerâmica própria com ajuda da esposa e do sogro em Tambaú (SP). Tentou abrir uma filial no Estado de Goiás, mas não foi bem sucedido. Hoje goza de um bom padrão de vida, tendo os seus sete filhos vivos a mesma condição.

O lazer mais comum para os entrevistados de primeira e segunda geração consistia nas reuniões familiares ou com amigos, nas festas religiosas ou das entidades portuguesas. Os entrevistados de terceira geração já apresentam hábitos comuns à maioria da população brasileira, como a prática de esportes, freqüência a festas e bares etc.

Para a comunidade portuguesa a transmissão dos seus valores e costumes teve uma importância fundamental na manutenção da coesão do grupo nos primeiros tempos, desempenhando entre os que chegaram mais recentemente o papel de manter vivo o sentimento de pertencimento ao grupo imigrante português. Foram compartilhadas e transmitidas várias figuras em comum entre os imigrantes, como salienta Paulo F. Monteiro: 
"A utilização do tema dos descobrimentos abre, como nenhum outro, as possibilidades de reinvenção tanto na dimensão do espaço como na do tempo. Do espaço, porque, precisamente, a dispersão dos portugueses pelos cantos do mundo seria uma tradição enraizadamente nacional, justificando assim que as comunidades políticas possam, hoje como no passado, estarem espacialmente dispersas, e existirem como 'nações desterritorializadas', identificadas com a população e não com o território. Reinvenção do tempo, porque as longas e tradicionais separações dos portugueses em relação à parte dos seus familiares exigiriam ser pensadas dentro de um quadro temporal alargado, em que a 'portugalidade' sobreviveria não só em lugares como em gerações muito afastadas da origem.” (Monteiro, 1994)

No Brasil os interesses e estratégias das elites políticas e religiosas pela tradição portuguesa são expressos pelo incentivo à afiliação a clubes de futebol, como a Portuguesa de Desportos em São Paulo e o Vasco da Gama no Rio de Janeiro, através da orientação aos descendentes de portugueses a torcer por esses times e a comprar produtos licenciados com a respectiva marca. Também empresas com interesses majoritariamente comerciais apelam para o espírito lusitano para atrair compatriotas.

De acordo com os relatos dos nossos entrevistados, havia no passado, principalmente nas comunidades rurais, festividades características de cada grupo imigrante, organizadas pelas paróquias com o intuito de angariar fundos para a construção ou ampliação de igrejas que recorriam ao sentimento e tradições lusitanos; cessada essa necessidade imediata por fundos, a importância das festas declinava e as datas nacionais passaram a não ser tão lembradas. Esse "esquecimento" de algumas tradições portuguesas pode levar em algum momento no futuro a seu renascimento, pois, como é apontado por Brandão (1986 p. 154), “ora, assim como algumas pessoas lembraram que uma identidade qualquer só se torna ativamente presente na consciência e na cultura de sujeitos e de um povo, quando eles se vêem ameaçados de perdê-la."

$\mathrm{E}$ pode ressurgir através de iniciativas do governo brasileiro ou português, em eventos culturais semelhantes aos já desenvolvidos no 
Sul do país com os descendentes de alemães e italianos, que criam oficinas culturais para preservar a cultura de determinado país e se apresentam por todo o país, promovendo festas características, como a Oktoberfest de origem alemã em Santa Catarina. Até na região de Campinas, von Simson (1999) constatou esse fenômeno de reconstituição de antigas tradições, como as danças típicas alemãs nas comunidades na zona rural.

Nas vinte e cinco entrevistas realizadas pelos pesquisadores deste sub-projeto, percebeu-se a grande importância da transmissão intergeracional de valores e tradições da cultura lusitana e que estes valores foram carregados por um longo período de tempo, tendo sido modificados em decorrência de alguma mudança na trajetória de vida, como a morte de um parente, o deslocamento para uma outra localidade, o casamento com um cônjuge de outro grupo étnico, ou mesmo as mudanças comportamentais da época. Os pais procuraram cultivar e preservar nos filhos os valores e tradições do povo luso, como o valor do trabalho, a honestidade, a religiosidade e a união da família.

Pesquisadores de famílias e grupos determinados observaram também que é comum designar-se um membro da família ou grupo para o papel de pacificador, consciência ou autoridade no passado familiar. No trabalho realizado por Bezerra (2001) sobre uma comunidade de descendentes de alemães, agrupados no chamado Bairro dos Pires em Limeira-SP, nota-se a importância do indivíduo que guarda a tradição do grupo: "na fala de um dos depoentes considerado como referência cultural do bairro, o 'guardião da memória', que não cansava de repeti-la a quem quisesse ouvir. Sempre que solicitado e em todas as comemorações feitas na igreja ou na escola, ele estava presente para contar a história da constituição do bairro e de suas instituições principais, repetindo sempre o mesmo discurso." Isso foi verificado em várias famílias cujos membros foram por nós entrevistados. Sempre ouvíamos: "A senhora deveria falar com..., pois é ele (ou ela) que sabe contar a história da família". Geralmente essa pessoa é o filho mais velho, que teve mais contato com os pais e dos quais ouviu inúmeras vezes o relato da trajetória familiar.

Ao longo dos anos, com o nascimento dos filhos, a criação de uma rede de contatos sociais e a aquisição de um patrimônio, os laços de identidade com Portugal tenderam a diminuir, constatando-se diferenças 
entre as gerações. Os entrevistados da primeira geração mostram possuir uma identidade dúbia, sentindo-se portugueses e brasileiros ao mesmo tempo, tendo alguns se naturalizado brasileiros. Mas, no geral, eles ainda possuem a identidade portuguesa, o que fica claro numa fala do Sr. Emílio: "Olha, o sangue não nega a raça. Eu sou sempre português, mas a minha segunda pátria é o Brasil."

Monteiro mostra que "a idéia de emigração tem subjacente a idéia de um retorno, e nisso se distingue da idéia de êxodo: o imigrante não é aquele que parte para outro país, é aquele que de alguma forma se mantêm ligado ao país de origem" (Monteiro, 1994, p. 7). Dos imigrantes portugueses radicados no Brasil que nos relataram sua história de vida, poucos foram os que adquiriram casas ou outros bens em Portugal ou demonstraram interesse em retornar a Portugal, muitas vezes devido ao fato de os filhos estarem estabelecidos no Brasil.

"C: O senhor nunca quis voltar a morar em Portugal?

E: Não tem condições com todos os filhos aqui. E se eu tivesse mais dinheiro teria, eu disse prá ela que eu iria comprar um apartamento em Portugal e ficar três ou quatro meses por ano lá e o resto aqui, isso não tem dúvida nenhuma. Eu gosto mais do clima de Portugal, da alimentação, da família, mas o Brasil... Inclusive já fiz o meu túmulo lá."

Isso os diferencia dos imigrantes portugueses radicados na Alemanha, na França ou nos Estados Unidos que, depois de algum tempo de trabalho árduo e tendo conseguido poupar algum recurso, adquirem em Portugal uma casa própria, bem confortável, ou iniciam um pequeno negócio.

No caso dos portugueses que vivem em países europeus, tinham um objetivo bem determinado ao irem trabalhar no estrangeiro: trabalhar por uns cinco anos, ganhar dinheiro e retornar à pátria. Com o passar do tempo, o objetivo a ser alcançado mudou e se tornou mais importante provar à população que havia ficado na aldeia que haviam tido sucesso no exterior e não viviam mais tão precariamente como os remanescentes em Portugal. Assim, eles compram ou constroem antes de qualquer coisa a casa que permanece vazia na aldeia e é ocupada por eles somente durante as férias. Estão bem conscientes da inveja de que 
são objeto por parte desses aldeões e nos dizem "somos chamados de alemães, quando vamos a Portugal". ${ }^{1}$

No Brasil, os de segunda e terceira geração sentem-se brasileiros mas nutrem um carinho todo especial por Portugal. Alguns se interessam pelo país e pelas histórias dos antepassados, mas sua pátria é o Brasil. Em contraposição ao trabalho mencionado efetuado na Alemanha com imigrantes portugueses, percebe-se a diferença no modo como as segundas e terceiras gerações foram criadas nos dois países. $\mathrm{Na}$ Alemanha a maioria dos pais agiu no sentido de preservá-los de contatos mais próximos com os alemães e isso significa que a mãe ou o filho mais velho tinha que acompanhar as filhas quando necessitavam sair e também a concessão de permissão somente para visitar ou convidar para a própria casa amigos de origem portuguesa. Se os pais conseguem esse intento, a identidade portuguesa dos filhos geralmente é preservada.

Já no Brasil os pais não tinham essa preocupação e os filhos tinham pouca restrição quanto à origem étnica dos seus amigos. No relato de um entrevistado de segunda geração, ele se recorda de apenas um amigo seu que era de origem portuguesa, o restante dos amigos sendo de origem italiana. Alguns descendentes interessaram-se em retirar passaporte português, mais com o intuito de poder viajar pela Europa com maior liberdade do que pelo orgulho de possuir um passaporte português ou motivado pelo desejo de morar lá.

Alguns deles vão perdendo com o tempo até o sotaque português. De acordo com o relato de um entrevistado português:

"C: Deu para perceber que o senhor perdeu totalmente o sotaque. Já não parece mais que é de origem portuguesa.

M: É que eu fiz o primário e a gente vai estudando por aí afora, né, e também tem a convivência e assim a gente muda."

Um fato inconteste a respeito dos entrevistados da terceira geração é que eles vão se distanciando cada vez mais dos valores e da cultura de

Essas observações foram feitas com base em estudo realizado em 1999 pela pesquisadora Maria Christina S. de Souza Campos na Alemanha, durante o qual foram entrevistados vinte e nove membros da comunidade portuguesa residente no Estado da Renânia do Norte/Westfália. 
Portugal e da família, já não vêem necessidade de manutenção das tradições tipicamente portuguesas, como a religiosidade, a comemoração das festas juninas e a reunião da família em datas especiais, evidenciando um individualismo comum nos tempos atuais.

\section{Considerações finais}

A facilidade de integração ou de adaptação dos portugueses a todas as situações pôde ser constatada nos relatos colhidos, mas por trás vêm à tona os preconceitos, a segregação velada de que foram ou ainda são vítimas e que impõem a outros que não alcançaram a mesma situação sócio-econômica. Neste último caso estão principalmente aqueles oriundos de zonas rurais do Norte de Portugal e dirigidos ao Brasil também para o trabalho na agricultura, chegados a partir do fim do século XIX até o fim das três primeiras décadas do século XX.

Mas aqueles que chegaram mais para o fim da primeira metade do século, vindos já com nível educacional mais elevado, embora não universitário, saídos de Portugal para fugir ao serviço militar e a uma forte ditadura, vêem-se como superiores a seus patrícios, mantêm laços estreitos com Portugal, laços esses que agora, mais do que nunca, após a entrada de Portugal na Comunidade Européia, não desejam romper. Ao contrário, incentivam os filhos a terem passaporte português, a viajarem para lá com freqüência, sendo eles os primeiros a levá-los e os pôr em contato com os parentes que lá restaram. Nesses a identidade portuguesa está viva, não havendo qualquer dúvida a respeito. Por isso vê-se que a questão da identidade também passa pelas imagens que ficam retidas na mente sobre como foi sua vida na pátria de origem, como é sua vida atual, as dificuldades enfrentadas no decorrer da trajetória familiar e o sucesso ou não para sua superação.

Como vimos, Sayad (1998) salienta a necessidade de se estudarem as condições sociais que engendraram a emigração e sua transformação para que se possa ter uma visão mais completa do fenômeno da emigração. As duas faces de uma mesma realidade a que se refere ao falar do fenômeno migratório dizem respeito à emigração e à imigração, pois esta é um prolongamento daquele fenômeno e perdurará enquanto a figura do imigrante não desaparecer, ou seja, enquanto ele e 
os que o cercam não o enxergarem como qualquer outro indivíduo dentro do país de adoção, sem nada que o distinga da população local. Nesse aspecto, podemos dizer que os imigrantes do primeiro período que consideramos (até 1930) já desapareceram enquanto imigrantes. Sentem-se brasileiros e são vistos como integrados à sociedade brasileira, apesar de alguns poucos ainda serem denominados de "português". Certamente já foi esquecido como emigrante pela sociedade de emigração, até antes que fosse chamado com o nome de imigrante no novo país. Pouca contribuição deu ao país de origem, dada a dificuldade de vida na nova terra. Quando as condições de vida se alteraram para melhor, já fazia muito tempo de sua vinda e os laços com os parentes na terra de origem tinham quase se rompido.

Outra questão a ser considerada é aquilo para o qual Sayad chamou a atenção: o fato de o discurso (científico ou não) sobre o imigrante e a imigração serem produto de uma problemática que é imposta de fora e à qual é difícil escapar, estando condenado, "para poder falar de seu objeto, a acoplá-lo a toda uma série de outros objetos ou de outros problemas" (Sayad, 1998, p. 14). Sayad salientou a esse respeito que esses fenômenos só podem ser captados e tratados através dos diferentes problemas a que se encontram associados, dificuldades, distúrbios, danos etc., sendo um “'fato social completo', única característica, aliás, em que há concordância na comunidade científica” (Ibid.). Evidentemente nenhum imigrante entrevistado deixou de ser produto da problemática que o fez decidir mudar de país. Os primeiros vieram mais impulsionados pela miséria na terra natal e ansiando pelo encontro de melhores condições de vida. Os outros, de modo geral, foram movidos por questões políticas e militares. Mas os primeiros encontraram no Brasil uma massa de "companheiros de luta", ou seja, imigrantes de outras nacionalidades que partilhavam igualmente da vida difícil que levavam, o que os fez ter coragem para enfrentar as adversidades no intuito de ir conquistando seu espaço e o respeito da população autóctone, ao mesmo tempo em que guardavam recursos para garantir um futuro melhor para si e para os filhos.

A determinação legal emanada de Getúlio Vargas em 1932, obrigando a maioria a se naturalizar, agiu certamente como uma forte imposição externa que acabou por "selar" definitivamente o destino desses imigrantes como membros da sociedade de adoção. A isso se acresce a 
miscigenação de que falamos, a participação econômica muito ativa na sociedade local, a interrupção ou o declínio dos fluxos migratórios, tendo como conseqüência uma maior integração no país de acolhimento e até, em muitos casos, a identificação com a nacionalidade brasileira.

Como o espaço do deslocamento não é somente um espaço físico, mas um espaço qualificado em muitos sentidos, social, econômica, política e culturalmente, aos poucos se verificou a ascensão mais econômica que social, conseguida por anos a fio através do trabalho de toda a família com a enxada. A melhoria das condições econômicas da família pode ser verificada pela casa em que moram, pelas doações feitas aos filhos, seja sob a forma de terras ou de propriedades na zona urbana. Gozam alguns, é certo, de prestígio na comunidade local em que vivem, mas esse prestígio não atinge a região, muito menos a comunidade portuguesa de maior projeção localizada na capital do Estado.

A sociedade brasileira que acolheu o imigrante assim o denominou no momento em que atravessou suas fronteiras, ignorando o que veio antes, a trajetória percorrida, a cultura de origem, mesmo porque estavam chegando muitos grupos de diferentes origens, vistos sempre no seu conjunto, sem individualização. Uma questão importante a se considerar refere-se à legitimação da imigração, que aparece tanto no discurso do imigrante, que procura encontrar razões para explicar e legitimar o abandono de sua terra natal, como no da própria sociedade de emigração, bem como no da sociedade de adoção. Assim são mencionadas várias causas da parte desta que justificariam a chamada ou, ao menos, a aceitação de levas de imigrantes em determinados momentos, enquanto que em outros as portas de entrada do país são bloqueadas (o que ficou evidente em certos momentos da história portuguesa): déficit demográfico, necessidade de mão-de-obra para a economia em expansão (seja de pessoal com nível mais elevado de qualificação, seja, ao contrário, demanda por pessoal sub-qualificado que se sujeite a trabalhos que a população autóctone não está disposta a realizar), para a obra de reconstrução de um país afetado pela guerra, entre outras formas de justificativa.

Nosso estudo permitiu constatar, além dos aspectos mencionados acima, a descontinuidade do processo migratório; há uma diferença nítida entre o comportamento da primeira e das gerações subseqüentes. Estas demonstram desinteresse pelas associações representativas da 
colônia portuguesa no interior do Estado de São Paulo, notando que não há sentido na preservação dos laços com a pátria de origem dos pais. Assim, não se pode falar na existência de qualquer núcleo português em Ribeirão Preto ou em qualquer outra cidade da macro-região. Apesar disso e, até de forma inconsciente para os próprios interessados, a educação familiar contribuiu significativamente para marcar no íntimo dos membros da segunda e terceira gerações alguns traços bem nítidos de origem portuguesa: valores cultivados, apego familiar, gosto por pratos da culinária portuguesa.

Entre os chegados nas décadas de 1930 e 1940, especialmente, nota-se maior orgulho em relação à pátria de origem, a manutenção da identidade portuguesa e dos laços com a família em Portugal. Visitas freqüentes, às vezes acompanhadas dos filhos, ajudam a fortalecer essa ligação e mostram o desejo forte de manter os filhos unidos a Portugal.

Tenta-se perpetuar as ilusões coletivamente mantidas, tanto na sociedade de emigração como na de imigração. Isso se torna muito evidente neste estudo. Em Portugal fala-se numa comunidade de língua a estar irmanando todas as populações que tiveram Portugal como metrópole geradora não só dessa língua, como de um complexo de tradições que, segundo muitos autores do passado já mencionados no projeto original, levam à existência de uma verdadeira união entre os povos da América, da África e da Ásia em torno de Portugal, a pátria-mãe. Isso, evidentemente, é uma ilusão não partilhada nem pelos e/imigrantes, nem pelas populações nacionais dos países de acolhimento. Segundo Monteiro (1994), mais recentemente há uma reinvenção do emigrante português, ele que já tinha sido colonizador também na qualidade de emigrante, no aspecto espacial e temporal até a segunda ou terceira gerações.

No Brasil, está presente a representação de um país aberto a todos os que o procuram, onde as oportunidades estão à mão, onde só não tem sucesso quem não quer. A investigação dos fenômenos migratórios vai aos poucos revelando a verdade por trás dessas ilusões e novas condições econômicas, sócio-culturais e políticas internas e externas às nações envolvidas, acabando por colocá-la à mostra, sendo os imigrantes os primeiros a mudarem o discurso. O prosseguimento deste trabalho para ir mais a fundo nessas questões e nas reflexões colocadas por Sayad, que, embora tenham por base seus estudos sobre os 
argelinos na França e em seu país de origem, pode dar margem a muitas investigações sobre os portugueses no Brasil.

Concluindo esta parte não se pode deixar de lembrar o quadro traçado por Boaventura Sousa Santos em sua obra Pela Mão de Alice (1995) sobre a cultura portuguesa, que traça uma visão realista de Portugal, salientando as contradições reinantes na história portuguesa e as imagens que seu povo faz de si mesmo, assim como as daqueles com os quais entram em contato. A heterogeneidade é uma marca tão forte quanto surpreendente numa nação de dimensões tão pequenas, expressa não só na diversidade de modos de vida que caracteriza os oriundos de diferentes regiões, como também na distância social que separa portugueses de diferentes classes sociais, o que dificulta a formação de comunidades mais integradas mesmo na zona rural, onde esse fenômeno costuma ocorrer com freqüência. Desunião, falta de solidariedade, preconceito, são traços dos imigrantes de que se queixam seus próprios compatriotas, segundo nos relataram vários neste estudo. Mas talvez seja esse traço aquilo que permita aos portugueses e seus descendentes se adaptarem tão bem e tão rapidamente às condições de vida da nação onde escolhem viver, já que não chegam a formar uma comunidade fechada e isolada dos integrantes da sociedade de acolhimento. É isso que os torna tão invisíveis e lhes facilita a vida onde quer que seja.

\section{Referências bibliográficas}

BEZERRA, Maria Cristina dos Santos. Imigração, educação e religião: Um estudo histórico-sociológico do bairro dos Pires de Limeira, uma comunidade rural de maioria teuto-brasileira. (Dissertação de Mestrado). Faculdade de Educação da UNICAMP, Campinas, 2001.

BOURDIEU, Pierre. Um Analista do Inconsciente. In: SAYAD, Abdelmalek. A Imigração. São Paulo: EDUSP, 1998, p. 9-12.

BRANDÃO, Carlos Rodrigues. Identidade e Etnia: construção da pessoa e resistência cultural. São Paulo: Brasiliense, 1986.

MONTEIRO, Paulo Filipe. Emigração: o eterno mito do retorno. Oeiras: Celta Editora, 1994.

ROCHA-TRINDADE, Maria Beatriz. Espaços de herança cultural portuguesa: gentes, factos, políticas. Análise Social, v. XXIV, n. 100, 313-51, 1988. 
SANTOS, Boaventura de Sousa. Pela Mão de Alice: o social e o político na pós-modernidade. Porto: Edições Afrontamento, 1994.

SAYAD, Abdelmalek . A Imigração. São Paulo: EDUSP, 1998.

STOLCKE, Verena. Cafeicultura: Homens, Mulheres e Capital (1850-1980). São Paulo: Brasiliense, 1986.

THOMPSON, Paul. A Transmissão Cultural entre Gerações dentro das Famílias: uma Abordagem Centrada em Histórias de Vida. Ciências Sociais Hoje. São Paulo, 9-19, 1993.

VON SIMSON, Olga Rodrigues de Moraes. Identidades Conjunturais x Identidade Tradicional: As Múltiplas Faces da Teuto-Brasilidade no Interior de São Paulo. Travessia, São Paulo, ano 12, n. 35, 5-9, set./dez 1999.

Resumo: Trata-se de um estudo qualitativo, baseando-se na coleta de relatos orais de portugueses e seus descendentes chegados ao Brasil na primeira metade do século XX e dirigidos à zona rural do Estado de São Paulo, bem como na análise de documentos, existentes seja em órgãos oficiais e entidades portuguesas, seja em poder das próprias famílias. Em uma abordagem sócio-antropológica, focalizaram-se diferentes campos: vida familiar, trabalho, educação, cultura, lazer, religião e política. Seu referencial teórico é o pensamento de Pierre Bourdieu.

Palavras-chave: imigração portuguesa; trabalho; educação; práticas e representações.

Portuguese immigrants in São Paulo's Countryside (1900-1950)

Abstract: This is a qualitative study based on the collection of oral histories of Portuguese immigrants and their descendants arrived in Brazil in the first half of $20^{\text {th }}$ century gone to the agricultural zone of the State of São Paulo, as well as on documental material, existing either in official institutions and Portuguese entities or with interviewee families. In a social-anthropological approach, this study focused on different fields: familiar life, work, education, culture, leisure, religion and politics. Its theoretical referencial is the thought of Pierre Bourdieu. These immigrants came from the North of Portugal, in its majority due to the economic difficulties found in the native land and the perspective of a better life in Brazil. They worked initially in coffee plantations, but as time went by a big part of them moved to the urban zone, where they dedicated themselves to the commerce and small industry.

Key words: Portuguese migration; work; education; practices; representations. 